Jurnal Dinamika Sosial Ekonomi Vol.21 No.2, Desember 2020 : 150-162

ISSN 1411-593X (print); ISSN 2721-3137 (online)

\title{
PROSES PEMBERDAYAAN MASYARAKAT MELALUI PROGRAM PEDULI LINGKUNGAN DI DUSUN SINGOSAREN DESA WUKIRSARI KECAMATAN IMOGIRI KABUPATEN BANTUL
}

\author{
Community Empowerment Process Through Peduli Lingkungan Program \\ In Singosaren, Wukirsari Village, Imogiri Subdistrict, Bantul
}

\author{
A'mas 'Ainun Rofiq, Eko Murdiyanto, Daru Retnowati \\ Program Studi Agribisnis Fakultas Pertanian \\ Universitas Pembangunan Nasional Veteran Yogyakarta \\ J1. SWK 104, Condongcatur, Kecamatan Depok, \\ Kabupaten Sleman, Yogyakarta, Indonesia \\ *email koresponden_amasrofik17@gmail.com
}

Diterima tanggal :12 September 2020 ; Disetujui tanggal : 20 September 2020

\begin{abstract}
This research aimed to study the process of community empowerment through Peduli Lingkungan Program in Singosaren, Wukirsari Village, Imogiri Subdistrict, Bantul. The purpose of the Peduli Lingkungan Program creation is to build awareness of Singosaren community to care about environmental hygiene and not to throw any more garbage into Tansah Bedjo Sewer. This research was a qualitative research with case study method and took informants purposively. The informants in this study were Tansah Bedjo Youth Group Vice President, Tansah Bedjo Youth Group members and Singosaren residents with Tansah Bedjo Vice President and its members as key informants. Data gathering technique was interview and documentations. Data validation technique obtained by triangulation of data collection technique and the data analyzing technique was data reduction, data display and conclusion drawing. The results of the study conclude that The community empowerment through Peduli Lingkungan Program in Singosaren, Wukirsari Village, Imogiri Subdistrict, Bantul is already reach power giving stage. The advice that can be given for the Peduli Lingkungan Program is that Tansah Bedjo Youth Group as the program facilitator was better created or holds fish processing activities from Tansah Bedjo Sewer to mothers in Singosaren so that could increase the income for them and their families, as well as those activities could be a replacement of the soap making activities from secondhand cooking oil or Daulat Dapur activities that were no sustainability.
\end{abstract}

Key Words : Empowerment, Peduli Lingkungan Program, Singosaren, Tansah Bedjo Youth Group members 
Jurnal Dinamika Sosisal Ekonomi, 21 (2) : 150-162

\begin{abstract}
ABSTRAK
Penelitian ini bertujuan untuk mengkaji proses pemberdayaan masyarakat melalui Program Peduli Lingkungan di Dusun Singosaren, Desa Wukirsari, Kecamatan Imogiri, Kabupaten Bantul. Tujuan diciptakannya Program Peduli Lingkungan adalah untuk menyadarkan masyarakat di Dusun Singosaren untuk peduli terhadap kebersihan lingkungan dan tidak membuang sampah lagi ke dalam Selokan Tansah Bedjo. Penelitian ini merupakan penelitian kualitatif dengan metode pelaksanaan studi kasus dan pengambilan informan secara purposif dengan informan Wakil Ketua Kelompok Pemuda Tansah Bedjo, anggota Kelompok Pemuda Tansah Bedjo dan warga di Dusun dengan Wakil Ketua Kelompok Pemuda Tansah Bedjo dan anggota Kelompok Pemuda Tansah Bedjo sebagai Informan kunci. Teknik pengumpulan data yang digunakan adalah wawancara dan dokumentasi. Keabsahan data yang diperoleh diuji dengan triangulasi teknik pengumpulan data dan analisis data dilakukan dengan menggunakan reduksi data, penyajian data dan penarikan kesimpulan. Hasil penelitian memberikan kesimpulan bahwa pemberdayaan masyarakat melalui Program Peduli Lingkungan di Dusun Singosaren, Desa Wukirsari, Kecamatan Imogiri, Kabupaten Bantul telah mencapai tahap pemberian daya. Saran yang dapat diberikan untuk Program Peduli Lingkungan yaitu sebaiknya Kelompok Pemuda Tansah Bedjo selaku fasilitator program menciptakan atau mengadakan kegiatan pengolahan ikan hasil panen dari Selokan Tansah Bedjo terhadap ibu-ibu di Dusun Singosaren sehingga dapat menambah pendapatan mereka dan keluarganya, serta kegiatan tersebut dapat menjadi pengganti kegiatan pembuatan sabun dari minyak goreng bekas atau kegiatan Daulat Dapur yang sudah tidak terdapat keberlanjutan.
\end{abstract}

Kata Kunci : Dusun Singosaren, Kelompok Pemuda Tansah Bedjo, Pemberdayaan, Program Peduli Lingkungan

\title{
PENDAHULUAN
}

Dusun Singosaren terletak di Desa Wukirsari, Kecamatan Imogiri, Kabupaten Bantul, Provinsi Daerah Istimewa Yogyakarta. Kondisi lingkungan di Dusun Singosaren terjaga dengan baik dikarenakan sangat jarangnya ditemukan sampah sehingga lingkungannya bersih serta banyaknya pohon yang tumbuh menjadikan dusun ini terasa asri dan sejuk. Dusun Singosaren memiliki lahan pertanian yang luas dan kondisi tanah yang cukup subur, sehingga mayoritas warga di dusun ini bekerja sebagai petani.

Dusun Singosaren memiliki sebuah selokan, yaitu Selokan Tansah Bedjo. Selokan Tansah Bedjo merupakan bagian dari anak aliran sungai Opak. Selokan Tansah Bedjo memiliki Panjang 100 meter dengan lebar 1,2 meter. Arti dari Selokan Tansah Bedjo sendiri adalah selokan yang selalu beruntung. Pemberian 
Rofiq et.al. Proses Pemberdayaan Masyarakat Melalui Program Peduli

nama selokan tersebut tidak lepas dari harapan masyarakat Dusun Singosaren agar Selokan Tansah Bedjo selalu memberi keberuntungan bagi masyarakat Dusun Singosaren. Selokan Tansah Bedjo memegang peranan penting yaitu sebagai sumber irigasi bagi lahan pertanian di Dusun Singosaren dan menjadi tempat untuk budidaya ikan.

Awalnya selokan Tansah Bedjo merupakan selokan yang kumuh karena tercemar oleh sampah. Penyebab dari pencemaran tersebut dikarenakan kebiasaan masyarakat Dusun Singosaren yang suka membuang sampah kedalam Selokan Tansah Bedjo. Akibat dari pencemaran tersebut adalah banjir akibat meluapnya air pada selokan, bau yang tidak sedap, selokan menjadi mampet dan tercemarnya sawah milik para petani di Dusun Singosaren.

Menanggapi hal tersebut serta mengingat bahwa selokan Tansah Bedjo memegang peranan penting bagi pertanian di Dusun Singosaren, maka kelompok pemuda yang ada di dusun tersebut, yaitu Kelompok Pemuda Tansah Bedjo menciptakan Program Peduli Lingkungan. Program Peduli Lingkungan bertujuan untuk menyadarkan warga Dusun Singosaren agar peduli terhadap kebersihan lingkungan dan tidak membuang sampah lagi ke Selokan Tansah Bedjo. Program Peduli Lingkungan juga diciptakan sebagai bentuk tanggapan akan keluh kesah para petani di Dusun Singosaren yang sawahnya tercemar sampah.

Program Peduli Lingkungan telah mengubah kebiasaan masyarakat Dusun Singosaren yang dulunya sering mencemari selokan kini telah tersadarkan akan pentingnya kebersihan Selokan Tansah Bedjo. Bentuk kesadaran tersebut yaitu semakin berkurangnya warga yang membuang sampah di selokan. Program Peduli Lingkungan juga telah memunculkan usaha baru serta tambahan pendapatan bagi masyarakat dan Dusun Singosaren. Melalui Program Peduli Lingkungan, masyarakat dibekali keterampilan untuk mengelola dan mengolah sampah-sampah mereka sehingga dapat memberikan nilai tambah. Tujuan penelitian ini adalah mengkaji proses pemberdayaan masyarakat melalui Program Peduli Lingkungan di Dusun Singosaren, Desa Wukirsari, Kecamatan Imogiri, Kabupaten Bantul.

\section{METODE PENELITIAN}


Jurnal Dinamika Sosisal Ekonomi, 21 (2) : 150-162

Lokasi penelitian berada di Dusun Singosaren, Desa Wukirsari, Kecamatan Imogiri, Kabupaten Bantul, Provinsi Daerah Istimewa Yogyakarta. Dusun Singosaren merupakan dusun yang terdapat program yang bernama Program Peduli Lingkungan yang diciptakan oleh Kelompok Pemuda Tansah Bedjo yang diterapkan pada Selokan Tansah Bedjo dan program ini bertujuan menyadarkan warga di Dusun Singosaren agar peduli terhadap kebersihan Selokan Tansah Bedjo dan lingkungan Dusun Singosaren. Waktu penelitian dilakukan dari bulan Oktober hingga bulan November 2019. Jenis penelitian yang digunakan adalah penelitian kualitatif dengan pendekatan studi kasus. Fokus penelitian yang diamati ialah proses pemberdayaan pada masyarakat di Dusun Singosaren melalui Program Peduli Lingkungan dari Kelompok Pemuda Tansah Bedjo. Teknik penentuan informan dilakukan dengan cara purposive sampling, yaitu teknik penentuan sampel/informan dengan pertimbangan tertentu dengan menggunakan informan yang ada dalam posisi terbaik untuk memperoleh informasi yang dibutuhkan.

Subjek penelitian dalam penelitian ini adalah sumber informasi atau orang yang paling paham mengenai data yang dibutuhkan. Subjek dalam penelitian ini adalah Wakil Ketua Kelompok Pemuda Tansah Bedjo dan anggota Kelompok Pemuda Tansah Bedjo serta warga di Dusun Singosaren. Pemilihan informan tersebut dilakukan karena pihak-pihak tersebut terlibat dan mengetahui program Peduli Lingkungan tersebut.

Teknik pengumpulan data yang digunakan dalam penelitian kualitatif adalah observasi langsung, wawancara mendalam, dan dokumentasi (Sugiyono, 2016). Pengujian keabsahan data dalam penelitian ini menggunakan triangulasi sumber untuk menguji kredibilitas data. Pengujian keabsahan data dengan triangulasi sumber dilakukan dengan mengecek data yang telah diperoleh melalui beberapa sumber berbeda dengan menggunakan suatu metode yang sama (Sugiyono, 2009). Miles dan Huberman (1984) mengemukakan bahwa akivitas dalam analisis data kualitatif dilakukan secara interaktif dan berlangsung secara terus menerus sampai tuntas. Analisis data yang dilakukan berupa pengumpulan data, reduksi data, penyajian data dan penarikan kesimpulan. 
Rofiq et.al. Proses Pemberdayaan Masyarakat Melalui Program Peduli

\section{HASIL DAN PEMBAHASAN}

Pemberdayaan masyarakat menurut Pressman et al. (1982) sebagai model pembangunan yang berbasis rakyat dengan menggerakkan partisipasi masyarakat bukan hanya essensial untuk mendukung kegiatan pembangunan kegiatan yang digerakkan pemerintah, tetapi juga agar masyarakat berperan lebih besar dalam kegiatan yang dilakukannya sendiri. Hal ini didukung dengan pernyataan Dwiyanto dan Jemadi (2013) yang menyatakan bahwa pemahaman mengenai konsep pemberdayaan tidak bisa dilepaskan dari pemahaman mengenai siklus pemberdayaan itu sendiri, karena pada hakikatnya pemberdayaan adalah sebuah usaha berkesinambungan untuk menempatkan masyarakat menjadi lebih proaktif dalam menentukan arah kemajuan dalam komunitasnya sendiri. Artinya program pemberdayaan tidak bisa hanya dilakukan dalam satu siklus saja dan berhenti pada suatu tahapan tertentu, akan tetapi harus terus berkesinambungan dan kualitasnya terus meningkat dari satu tahapan ke tahapan berikutnya. Tujuan akhir dari proses pemberdayaan masyarakat menurut Widjajanti (2011) adalah untuk memandirikan warga masyarakat agar dapat meningkatkan taraf hidup keluarga dan mengoptimalkan sumberdaya yang dimilikinya. Pengkajian proses pemberdayaan masyarakat menurut Wrihatnolo dan Dwidjowijoto (2007) terdiri dari tiga tahapan yaitu tahap penyadaran, tahap pengkapasitasan dan tahap pemberian daya.

\section{Penyadaran terhadap Masyarakat di Dusun Singosaren melalui Program Peduli Lingkungan}

Penyadaran merupakan tahap dimana masyarakat diberi pengetahuan yang bersifat kognitif, belief dan healing. Prinsip dasarnya adalah membuat target mengerti bahwa mereka perlu diberdayakan dan proses pemberdayaan tersebut dimulai dari dalam diri mereka (bukan dari orang luar). Hal ini didukung dengan pernyataan Suyatno dan Dewi (2018) yang menyatakan bahwa tahap penyadaran dilakukan dengan memberikan pengetahuan kepada masyarakat yang bersifat mengajak, memberikan informasi yang menyakinkan dan dapat dipercaya sehingga dapat membuat masyarakat mau melakukan kegiatan pemberdayaan. Tahap penyadaran terbagi menjadi tiga yaitu secara kognitif, belief dan healing. 
Tahap penyadaran berupa kognitif berupa kegiatan sosialisasi dan forum diskusi dilakukan oleh Kelompok Pemuda Tansah Bedjo pada Februari tahun 2017 dengan memberikan materi tentang 3R (reuse, reduce, recycle) terhadap masyarakat di Dusun Singosaren yang dilaksanakan di Sanggar Anak Jaman dan di halaman pinggir Selokan Tansah Bedjo. Bulan Mei tahun 2017 Kelompok Pemuda Tansah Bedjo mengundang Bumi Langit untuk untuk melakukan sosialisasi dan memberikan materi tentang bahaya sampah terhadap masyarakat di Dusun Singosaren yang dilaksanakan di halaman pinggir Selokan Tansah Bedjo dan Sanggar Anak Jaman. Bulan Agustus 2017 Wakil Bupati Bantul memberikan bantuan dana sekaligus menyampaikan pidato bertema "Nek Lingkungane Resik, Uripe Penak" terhadap masyarakat di Dusun Singosaren yang dilaksanakan di halaman pinggir Selokan Tansah Bedjo. Kegiatan sosialisasi dan pemberian materi tentang bahaya sampah terhadap masyarakat di Dusun Singosaren oleh Bumi Langit dapat dilihat pada gambar 1.

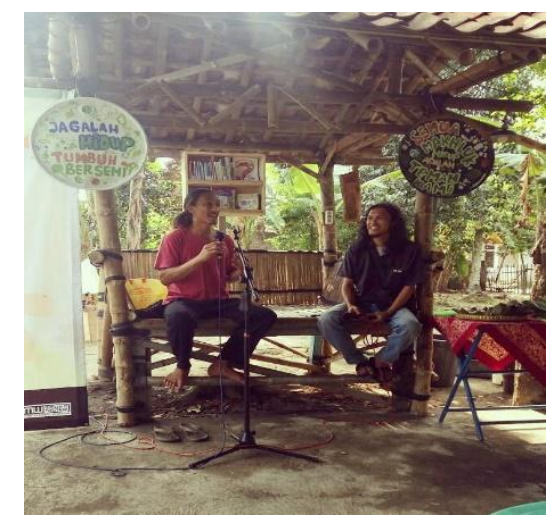

(Gambar 1. Sosialisasi dan Pemberian Materi Tentang Bahaya Sampah oleh Bumi Langit)

(Sumber : Facebook Kelompok Pemuda Tansah Bedjo (2017))

Tujuan sosialisasi dan pemberian materi tentang 3R (reuse, reduce, recycle) oleh Kelompok Pemuda Tansah Bedjo bertujuan agar masyarakat Dusun Singosaren dapat mengelola sampah yang mereka buang. Pemberian sosialisasi dan pemberian materi tentang bahaya sampah oleh Bumi Langit bertujuan untuk meningkatkan kesadaran masyarakat Dusun Singosaren untuk selalu menjaga kebersihan lingkungannya. Penyampaian pidato bertema "Nek Lingkungane Resik, Uripe Penak" bertujuan untuk memberikan dukungan moral kepada masyarakat 
Rofiq et.al. Proses Pemberdayaan Masyarakat Melalui Program Peduli

Dusun Singosaren agar semakin semangat menjaga kebersihan lingkungan Dusun Singosaren.

Tahap penyadaran yang berupa belief dilakukan oleh Kelompok Pemuda Tansah Bedjo dengan melakukan beberapa kegiatan. Kegiatan yang dilakukan oleh Kelompok Pemuda Tansah Bedjo antara lain dengan mengajak masyarakat Dusun Singosaren untuk ikut serta dalam kegiatan panen ikan di Selokan Tansah Bedjo, mengajak masyarakat untuk selalu menjaga kebersihan lingkungan serta mengumpulkan barang bekas keliling untuk dijual dan hasil penjualan barang bekas tersebut di kembalikan kepada warga. Kegiatan Kelompok Pemuda Tansah Bedjo dan masyarakat di Dusun Singosaren dapat dilihat pada gambar 2.

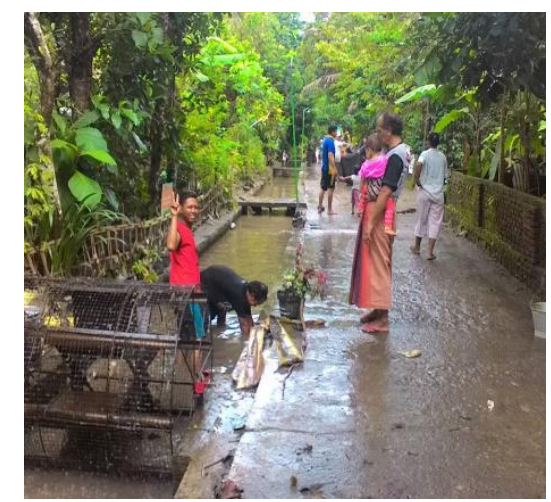

(Gambar 2. Kerja Bakti Membersihkan Selokan Tansah Bedjo oleh Kelompok

Pemuda Tansah Bedjo dan masyarakat di Dusun Singosaren)

(Sumber : Facebook Kelompok Pemuda Tansah Bedjo (2018))

Kegiatan yang dilakukan oleh Kelompok Pemuda Tansah Bedjo yaitu dengan mengajak masyarakat Dusun Singosaren untuk ikut serta dalam kegiatan panen ikan di Selokan Tansah Bedjo, mengajak masyarakat untuk selalu menjaga kebersihan lingkungan dan mengumpulkan barang bekas keliling untuk dijual bertujuan agar masyarakat di Dusun Singosaren menjadi semakin percaya dan optimis terhadap Program Peduli Lingkungan. Tidak terdapat tahap penyadaran berupa healing dikarenakan masyarakat Dusun Singosaren tidak meraa khawatir dengan adanya Program Peduli Lingkungan. Hal ini dikarenakan masyarakat di Dusun Singosaren sepenuhnya menyadari bahwa Program Peduli Lingkungan bertujuan untuk kebaikan bersama dan untuk kebaikan Dusun Singosaren. 
Jurnal Dinamika Sosisal Ekonomi, 21 (2) : 150-162

Pengkapasitasan terhadap Masyarakat di Dusun Singosaren melalui Program Peduli Lingkungan

Pengkapasitasan merupakan tahap peningkatan kapasitas atau sering disebut dengan capacity building. Pengkapasitasan merupakan peningkatan kapasitas masyarakat melalui pelatihan, sosialisasi dan sejenisnya. Hal ini didukung dengan pernyataan Nugroho (2017) yang menyatakan bahwa tahap pengkapasitasan dilakukan dengan memberikan pelatihan-pelatihan, lokakarya dan kegiatan sejenisnya yang bertujuan untuk meningkatkan lifeskill dari masyarakat. Pengkapasitasan terhadap masyarakat di Dusun Singosaren melalui Program Peduli Lingkungan yang dilakukan oleh Kelompok Pemuda Tansah Bedjo yaitu berupa pengkapasitasan manusia.

Pengkapasitasan manusia terhadap masyarakat di Dusun Singosaren melalui Program Peduli Lingkungan dilaksanakan dengan mengadakan pelatihan pembuatan sabun dari minyak goreng bekas terhadap ibu-ibu di Dusun Singosaren dengan nama kegiatannya yaitu Daulat Dapur. Pelaksanaan kegiatan Daulat Dapur dilakukan oleh Kelompok Pemuda Tansah Bedjo pada awal bulan Februari 2019 dengan mengundang Mbak Galuh selaku owner Sekartaji Pawon Studio untuk memberikan sosialisasi dan pelatihan pembuatan sabun dari minyak goreng bekas. Pelatihan ini dilaksanakan di halaman pinggir Selokan Tansah Bedjo dan di Sanggar Anak Jaman dengan dihadiri oleh ibu-ibu di Dusun Singosaren. Kegiatan sosialisasi pembuatan sabun minyak goreng bekas atau kegiatan Daulat Dapur dapat dilihat pada gambar 3 . 


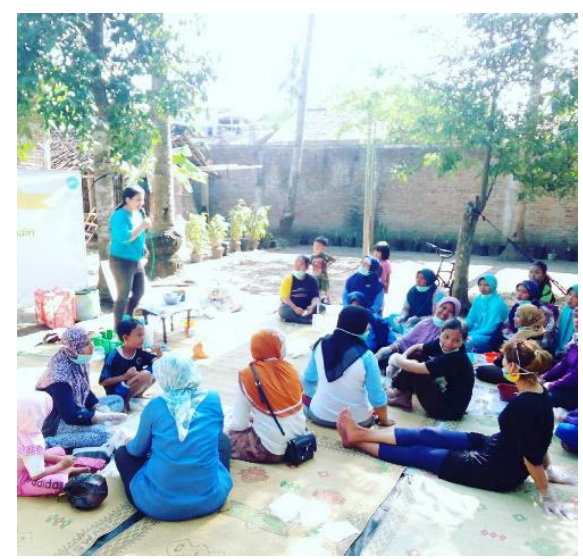

(Gambar 3. Sosialisasi Pembuatan Sabun dari Minyak Goreng Bekas oleh Mbak Galuh)

(Sumber : Facebook Kelompok Pemuda Tansah Bedjo (2019))

Pelatihan pembuatan sabun dari minyak goreng bekas atau kegiatan Daulat Dapur tersebut dilaksanakan karena banyaknya sampah minyak goreng bekas yang ada di Selokan Tansah Bedjo. Kegiatan Daulat Dapur bertujuan menjadikan sampah minyak goreng bekas tersebut menjadi barang yang berguna berupa sabun sehingga mengurangi pencemaran pada Selokan Tansah Bedjo. Namun, kegiatan Daulat Dapur ini tidak ada keberlanjutan dikarenakan ibu-ibu di Dusun Singosaren sudah tidak memiliki minat untuk membuat sabun dari minyak goreng bekas lagi dan lebih memilih untuk membeli sabun yang ada di warung-warung.

\section{Pemberian Daya terhadap Masyarakat di Dusun Singosaren melalui Program Peduli Lingkungan}

Pemberian daya atau empowerment merupakan tahap dimana masyarakat diberi daya, kekuasaan, otoritas atau peluang. Hal ini didukung dengan pernyataan Wahyuni (2018) yang menyatakan bahwa pada tahap pemberian daya masyarakat diberikan daya atau peluang untuk berkembang mencapai tahap kemandirian. Pemberian daya yang dilakukan oleh Kelompok Pemuda Tansah Bedjo kepada masyarakat di Dusun Singosaren yaitu berupa pemberian wewenang kepada masyarakat Dusun Singosaren dan anggota kelompoknya berupa kebebasan dalam berinovasi, berkreasi dan menyalurkan ideide kreatif mereka pada Selokan Tansah Bedjo asalkan memberikan dampak yang positif serta memberikan kebebasan 
kepada ibu-ibu di Dusun Singosaren untuk membuat sabun dari minyak goreng bekas secara mandiri.

Pemberian wewenang oleh Kelompok Pemuda Tansah Bedjo terhadap anggota kelompoknya dan masyarakat di Dusun Singosaren yaitu agar anggota Kelompok Pemuda Tansah Bedjo dan masyarakat Dusun Singosaren dapat berinovasi, berkreasi, menyalurkan ide-ide mereka dan mengeksplorasi kemampuan mereka untuk bergerak pada Program Peduli Lingkungan. Pemberian wewenang juga dilakukan untuk memajukan Program Peduli Lingkungan. Pemberian wewenang kepada ibu-ibu di Dusun Singosaren adalah agar mereka dapat mengolah minyak goreng bekas yang mereka buang secara mandiri sehingga lingkungan Dusun Singosaren bersih dari pencemaran limbah minyak goreng bekas.

Pemberdayaan melalui Program Peduli Lingkungan telah mencapai tahap pemberian daya dikarenakan Kelompok Pemuda Tansah Bedjo telah memberikan kewenangan secara penuh kepada ibu-ibu di Dusun Singosaren untuk membuat sabun dari minyak goreng bekas secara mandiri tanpa adanya pengawasan oleh Kelompok Pemuda Tansah Bedjo. Hal ini berarti Kelompok Pemuda Tansah Bedjo percaya sepenuhnya kepada ibu-ibu di Dusun Singosaren bahwa mereka dapat membuat sabun dari minyak goreng bekas secara mandiri. Hal ini didukung dengan pernyataan Endah (2020) yang menyatakan bahwa suatu pemberdayaan dapat dikatakan telah mencapai tahap pemberian daya jika masyarakat diberikan wewenang atau peluang untuk berkembang mencapai kemandirian dan pemberian daya disesuaikan dengan kualitas kecakapan masing-masing individu. Proses pemberdayaan masyarakat di Dusun Singosaren melalui Program Peduli Lingkungan dapat dilihat pada gambar 4. 


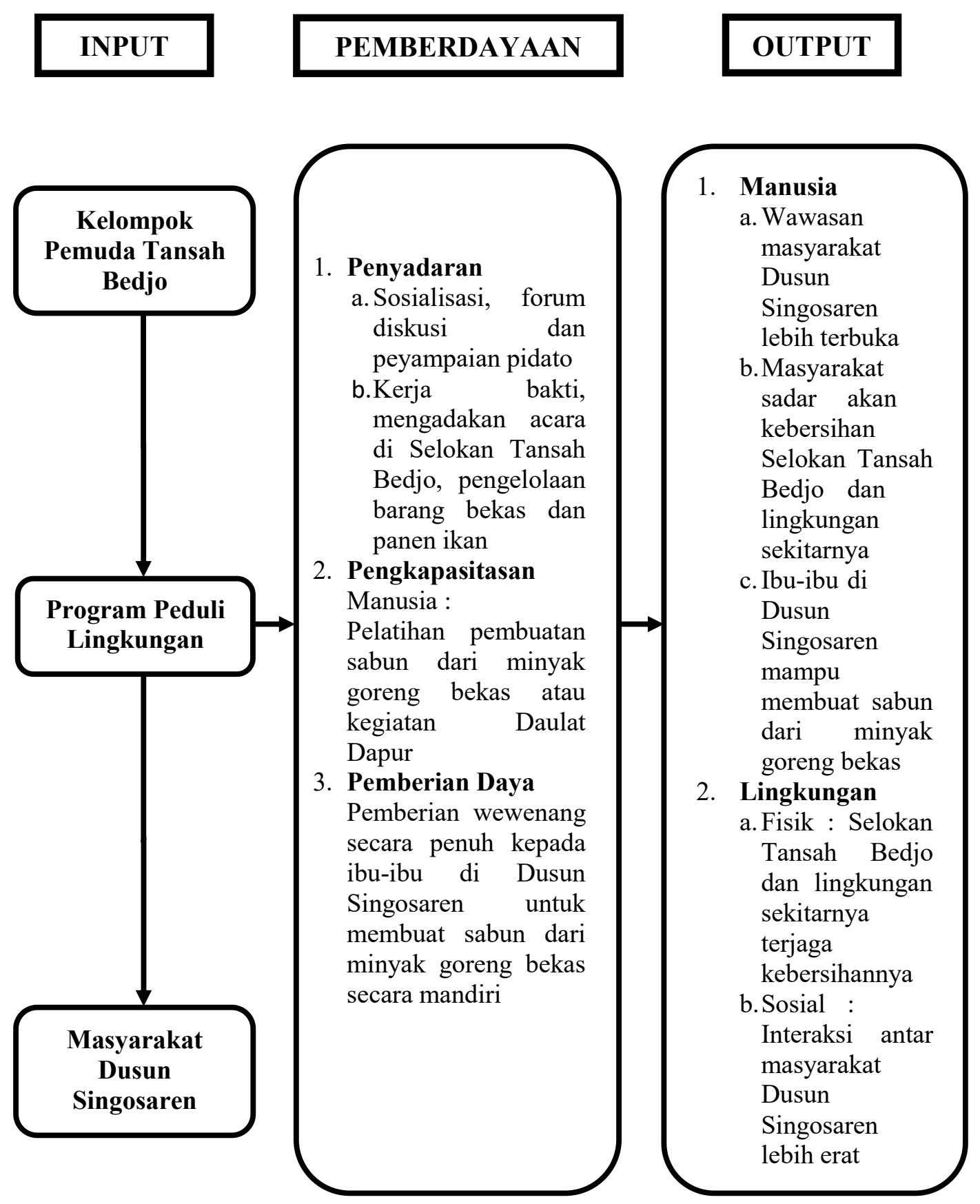

(Gambar 4. Proses Pemberdayaan Masyarakat di Dusun Singosaren melalui Program Peduli Lingkungan) 
Jurnal Dinamika Sosisal Ekonomi, 21 (2) : 150-162

\section{KESIMPULAN DAN SARAN}

\section{Kesimpulan}

Pemberdayaan masyarakat di Dusun Singosaren melalui Program Peduli Lingkungan telah mencapai tahap pemberian daya. Hal ini dapat diketahui dengan adanya kewenangan yang diberikan secara penuh oleh Kelompok Pemuda Tansah Bedjo kepada ibu-ibu di Dusun Singosaren untuk membuat sabun dari minyak goreng bekas secara mandiri tanpa adanya pengawasan oleh Kelompok Pemuda Tansah Bedjo.

\section{Saran}

Sebaiknya Kelompok Pemuda Tansah Bedjo selaku fasilitator Program Peduli Lingkungan menciptakan atau mengadakan suatu kegiatan pengolahan ikan hasil panen dari Selokan Tansah Bedjo terhadap ibu-ibu di Dusun Singosaren sehingga dapat menambah pendapatan ibu-ibu di Dusun Singosaren dan keluarga mereka, serta kegiatan tersebut sebagai pengganti kegiatan pembuatan sabun dari minyak goreng bekas atau kegiatan Daulat Dapur yang sudah tidak terdapat keberlanjutan.

\section{DAFTAR PUSTAKA}

Dwidjowijoto, N. Riant dan Wrihatnolo R. Randy. (2007). Manajemen Pemberdayaan. Jakarta: Elex Media Komputindo.

Dwiyanto dan Jemadi. (2013). Pemberdayaan Masyarakat dan Pengembangan Kapasitas dalam Penanggulangan Kemiskinan Melalui PNPM Mandiri Perkotaan. Jurnal MASKIPRENEUR, 3 (1). 36-61.

Endah, Kiki. (2020). Pemberdayaan Masyarakat : Menggali Potensi Lokal Desa. Jurnal Moderat, 6 (1). 135-143.

Miles, M. B. \& Huberman A. M. (1982). Analisis Data Kualitatif. Terjemahan oleh Tjetjep Rohendi Rohidi. Jakarta: Penerbit Universitas Indonesia.

Nugroho, Bagas Prasetyo. (2017). Pemberdayaan Masyarakat Eks Lokalisasi Dolly Melalui Pengembangan Wirausaha Oleh Pemerintah Kota Surabaya. Jurnal Kebijakan dan Manajemen Publik, 5 (2). 1-11.

Pressman, Jeffrey dan Wildavsky, Aaron. (1982). Bureaucracy and Policy Implementation. Los Angeles: University of California Press.

Sugiyono. (2009). Metode Penelitian Kuantitatif, Kualitatif dan $R \&$ D. Bandung: PT. Alfabet.

Sugiyono. (2016). Metode Penelitian Kuantitatif, Kualitatif dan R \& D. Bandung: PT. Alfabet. 
Rofiq et.al. Proses Pemberdayaan Masyarakat Melalui Program Peduli

Suyatno, Adi dan Utami Dewi S. I. P., M. PP. (2018). Pemberdayaan Masyarakat Melalui Pengembangan Desa Wisata Minapadi Di Kecamatan Seyegan. Jurnal Pemberdayaan Masyarakat, 7 (1). 1-14.

Wahyuni, Dinar. (2018). Strategi Pemberdayaan Masyarakat dalam Pengembangan Desa Wisata Nglanggeran, Kabupaten Gunung Kidul. Jurnal Masalah-Masalah Sosial, 9 (1). 83-100.

Widjajanti, Kesi. (2011). Model Pemberdayaan Masyarakat. Jurnal Ekonomi Pembangunan, 12. 15-27. 